\title{
Effect of ZnO loading technique on textural characteristic and methyl blue removal capacity of exfoliated graphite/ $\mathrm{ZnO}$ composites
}

\author{
XUEQING YUE ${ }^{\dagger, \dagger \dagger}$, WENYAN DUAN ${ }^{\dagger \dagger}$, YAN LU ${ }^{\dagger \dagger}$, FUCHENG ZHANG ${ }^{\dagger \dagger}$ and \\ RUIJUN ZHANG ${ }^{\dagger,+\dagger, *}$ \\ †State Key Laboratory of Metastable Materials Science and Technology, Yanshan University, \\ Qinhuangdao 066004, P.R. China \\ ${ }^{\dagger}$ Qinhuangdao Vocational and Technical College, Qinhuangdao 066100, P.R. China
}

MS received 28 September 2009; revised 17 February 2011

\begin{abstract}
Two exfoliated graphite/ZnO composites, marked as EG/ZnO-1 and EG/ZnO-2, were prepared by heating a mixture of expandable graphite and $\mathrm{Zn}(\mathrm{OH})_{2}$ or a mixture of expanded graphite (EG) and $\mathrm{Zn}(\mathrm{OH})_{2}$, respectively. The composites were characterized by scanning electron microscopy (SEM), X-ray diffraction (XRD) and nitrogen adsorption. Under UV irradiation, the composites were used for removing methyl blue (MB) from aqueous solution. For the composites made from expandable graphite (EG/ZnO-1), the micronsized $\mathrm{ZnO}$ particle agglomerates $(1-20 \mu \mathrm{m})$ heterogeneously distributed at the surface of graphite flakes, while for the composites made from EG (EG/ZnO-2), the submicron-sized $\mathrm{ZnO}$ particle masses (0.2-0.5 $\mu \mathrm{m})$ almost homogeneously located both at the surface and interior of graphite flakes. In the presence of UV irradiation, the composites had the adsorption capacity of EG and the photocatalysis capacity of $\mathrm{ZnO}$ at the same time. Compared with EG/ZnO-1, EG/ZnO-2 was more effective in removing MB. After $2 \mathrm{~h}$ of $\mathrm{UV}$ irradiation, MB could be completely removed by using the $\mathrm{EG} / \mathrm{ZnO}-2$ containing $45 \% \mathrm{ZnO}$, and the decomposition efficiency of the $\mathrm{ZnO}$ was the primary cause for the removal of $\mathrm{MB}$.
\end{abstract}

Keywords. Exfoliated graphite/ZnO; adsorption; decomposition; methyl blue.

\section{Introduction}

Wastewater containing various dyes is one of the major industrial pollutants. The photocatalytic decomposition of organic pollutants in wastewater received considerable research attention. Among the photocatalysts studied for their photocatalytic properties, $\mathrm{TiO}_{2}$ is the most commonly used photocatalyst for its high efficiency, low cost, nontoxicity and photochemical stability. Recently, another photocatalyst, $\mathrm{ZnO}$, is receiving great attention from researchers (Yeber et al 1999; Lizama et al 2002; Quintana et al 2002; Daneshvar et al 2003, Wang et al 2008). It was proved that $\mathrm{ZnO}$ displayed a similar photodegradation mechanism as $\mathrm{TiO}_{2}$ and therefore was proposed as a suitable alternative to $\mathrm{TiO}_{2}$.

Exfoliated graphite (EG) is an excellent inorganic carbon material with a porous structure, which has many characteristics including low density, non-toxicity, nonpollution and easy disposal. Because of its porous structure, this material has been used as an absorbent for removing organic pollutants from wastewater, such as oils, biomedical liquids and dyes (Chung 1987; Toyoda and Inagaki 2000; Kang et al 2003; Tryba et al 2003, Zheng et al 2004; Li et al 2007). Moreover, EG is an excellent

\footnotetext{
*Author for correspondence (yuexueqing@126.com)
}

support for loading photocatalysts (Savoskin et al 2006; Shornikova et al 2008; Yue et al 2008).

$\mathrm{EG} / \mathrm{ZnO}$ composites used in the discussion of this paper were prepared by using two different $\mathrm{ZnO}$-loading methods. We attempted to investigate the effect of $\mathrm{ZnO}$ loading methods on the texture characteristics and methyl blue (MB) removal capacities of the composites.

\section{Experimental}

\subsection{Materials}

Natural flake graphite (35 mesh, 99\% purity, possible contaminants including silica, thorium and iron) was purchased from Qingdao Tianhe Graphite Company, China. Zn $\left(\mathrm{NO}_{3}\right)_{2} \cdot 6 \mathrm{H}_{2} \mathrm{O}$, sulphuric acid $(98 \%)$, hydrogen peroxide (30\%), $\mathrm{CO}\left(\mathrm{NH}_{2}\right)_{2}$, ethanol and distilled water were of laboratory reagent grade and used without further purification.

\subsection{Preparation of the composites}

Natural flake graphite (6 g) was mixed with sulphuric acid as the intercalation agent $(10 \mathrm{ml})$ and hydrogen peroxide as the oxidizing agent $(1.0 \mathrm{ml})$. The mixture was left to stand at $50^{\circ} \mathrm{C}$ for $90 \mathrm{~min}$, washed to $\mathrm{pH} \mathrm{5-7}$ and 
dried at $70^{\circ} \mathrm{C}$ for $24 \mathrm{~h}$, forming expandable graphite. EG could be obtained by abruptly heating the expandable graphite at $700^{\circ} \mathrm{C}$ for $40 \mathrm{~s}$. The reaction equations for the preparation of $\mathrm{ZnO}$ could be described as follows:

$$
\begin{aligned}
& \mathrm{CO}\left(\mathrm{NH}_{2}\right)_{2}+3 \mathrm{H}_{2} \mathrm{O} \stackrel{\Delta}{\rightarrow} \mathrm{CO}_{2} \uparrow+2 \mathrm{NH}_{3} \cdot \mathrm{H}_{2} \mathrm{O}, \\
& \mathrm{Zn}^{2+}+\mathrm{NH}_{3} \cdot \mathrm{H}_{2} \mathrm{O} \rightarrow \mathrm{Zn}(\mathrm{OH})_{2} \downarrow+2 \mathrm{NH}_{4}^{+}, \\
& \mathrm{Zn}(\mathrm{OH})_{2} \stackrel{\Delta}{\rightarrow} \mathrm{ZnO}+\mathrm{H}_{2} \mathrm{O} \uparrow .
\end{aligned}
$$

According to the (1) and (2), $\mathrm{Zn}(\mathrm{OH})_{2}$ was prepared as follows: in a $1000 \mathrm{ml}$ conical flask, $\mathrm{Zn}\left(\mathrm{NO}_{3}\right)_{2} \cdot 6 \mathrm{H}_{2} \mathrm{O}$ $(0 \cdot 1 \mathrm{~mol} / \mathrm{l})$ and $\mathrm{CO}\left(\mathrm{NH}_{2}\right)_{2}(0.3 \mathrm{~mol} / \mathrm{l})$ were dissolved in $500 \mathrm{ml}$ distilled water under vigorous stirring at room temperature, dispersed by ultrasonication for $10 \mathrm{~min}$, which resulted in a transparent solution. The transparent solution was stirred at $90^{\circ} \mathrm{C}$ for $3 \mathrm{~h}$, forming a milk-like liquid. After stirring, the milk-like liquid was cooled to the room temperature, which resulted in the formation of white precipitate at the bottom of the conical flask. To get $\mathrm{Zn}(\mathrm{OH})_{2}$, the white precipitate was collected by centrifugation and washed successively by distilled water and ethanol. According to the (3), $\mathrm{ZnO}$ could be obtained by heating the $\mathrm{Zn}(\mathrm{OH})_{2}$ at $400^{\circ} \mathrm{C}$ for $3 \mathrm{~h}$. A tunnelling electron microscopy (TEM) examination showed that the $\mathrm{ZnO}$ as-prepared was in the form of spherical particles with size of $40-60 \mathrm{~nm}$ and X-ray diffraction (XRD) measurement revealed that the structure resembled hexagonal wurtzite $\mathrm{ZnO}$ (the corresponding figures were not present here).

EG/ZnO-1 was prepared as follows: expandable graphite was mixed with $\mathrm{Zn}(\mathrm{OH})_{2}$ solution, placed at $30-40^{\circ} \mathrm{C}$ for 3 days and dried at $70^{\circ} \mathrm{C}$ for $24 \mathrm{~h}$, and finally heated at $700^{\circ} \mathrm{C}$ for $40 \mathrm{~s}$ and $400^{\circ} \mathrm{C}$ for $3 \mathrm{~h}$. EG/ZnO-2 was prepared as follows: EG was mixed with $\mathrm{Zn}(\mathrm{OH})_{2}$ solution, placed at $30-40^{\circ} \mathrm{C}$ for 3 days and dried at $70^{\circ} \mathrm{C}$ for $24 \mathrm{~h}$, and finally heated at $400^{\circ} \mathrm{C}$ for $3 \mathrm{~h}$. By changing the concentration of $\mathrm{Zn}\left(\mathrm{NO}_{3}\right)_{2} \cdot 6 \mathrm{H}_{2} \mathrm{O}$, the $\mathrm{ZnO}$ content in the composites $\left(\mathrm{W}_{\mathrm{ZnO}}, \mathrm{wt} \%\right)$ was controlled, which was measured by the complex titration analysis method. It was found that the permissible $\mathrm{ZnO}$ contents for $\mathrm{EG} / \mathrm{ZnO}-1$ and $\mathrm{EG} / \mathrm{ZnO}-2$ were about 35 and $85 \%$, respectively.

\subsection{Characterization of the composites}

The phase composition of the composites was determined by X-ray diffraction (D/max-rB, Rigaku, Japan) (CuK $\alpha$, $40 \mathrm{kV}, 40 \mathrm{~mA}, 10-80^{\circ}, 0.02$ step, $10 \mathrm{~s} \mathrm{step}^{-1}$ ). Scanning electron microscopy (SEM, KY2828 type) was used to observe the morphology. Specific surface areas $\left(S_{\mathrm{BET}}\right)$ were measured by physical nitrogen adsorption measurement at $77 \mathrm{~K}$.

\subsection{Removal of MB by the composites}

At room temperature, a $200 \mathrm{ml}$ beaker was charged with MB aqueous solution $(150 \mathrm{ml})$ at a concentration of
$10 \mathrm{mg} / \mathrm{l}$ and the composites $(0 \cdot 15 \mathrm{~g})$. The solution $(\mathrm{pH}=7)$ was irradiated by a $30 \mathrm{~W}$ mercury lamp (UV-C, Philips) for $3 \mathrm{~h}$. The UV lamp was positioned parallel to the solution, and the distance between the top of the solution and the UV lamp was constant $(15 \mathrm{~cm})$. UV-2501PC (Shimadzu, Japan) UV-Vis spectrometer (at $\lambda_{\max } 665 \mathrm{~nm}$ ) was used to observe the removal of MB. For comparison, this solution was also placed for $3 \mathrm{~h}$ in the absence of UV irradiation. In the absence (or presence) of UV irradiation, the adsorption efficiency (or removal efficiency) was calculated by using the following equation:

Adsorption efficiency (or removal efficiency)

$$
=\left(A_{665, i}-A_{665, t}\right) / A_{665, t},
$$

where $A_{665, i}$ is the absorbance of initial MB solution at $665 \mathrm{~nm} ; A_{665, t}$ is the absorbance $(665 \mathrm{~nm})$ at measurable time $t$.

Decomposition efficiency of the composites could be approximately denoted as

Decomposition efficiency $=$ removal efficiency - adsorption efficiency.

\section{Results and discussion}

\subsection{SEM of the composites}

Representative SEM micrographs (figure 1) show the surface and interior structures of the composites. For $\mathrm{EG} / \mathrm{ZnO}-1$, the micron-sized $\mathrm{ZnO}$ particle agglomerates (1-20 $\mu \mathrm{m})$ heterogeneously located at the surface of graphite flakes, as shown in figure $1(\mathrm{a}, \mathrm{b})$. For EG/ZnO2 , however, the submicron-sized $\mathrm{ZnO}$ particle masses $(0.2-0.5 \mu \mathrm{m})$ almost homogeneously located both at the surface and interior of graphite flakes, as shown in figure 1(c, d). The inner pores between the flakes were partly filled by $\mathrm{ZnO}$ particles, which decreased the total amount of the open pores. These observations could be explained by the difference between the preparation processes of the two composites. When expandable graphite was impregnated by $\mathrm{Zn}(\mathrm{OH})_{2}$ solution, most of $\mathrm{Zn}(\mathrm{OH})_{2}$ would locate at the surface of graphite flakes because most of graphite layers were closed (Yue et al 2008), and consequently most of the $\mathrm{ZnO}$ particles in EG/ZnO-1 located at the surface of graphite flakes. A study (Inagaki et al 2003) showed that most of the pores in EG were opened, and the porosity of the closed pores was less than $1 \%$. As a consequence, $\mathrm{Zn}(\mathrm{OH})_{2}$ could easily enter into the interior of graphite flakes when EG was mixed with $\mathrm{Zn}(\mathrm{OH})_{2}$ solution. The difference between the permissible $\mathrm{ZnO}$ contents of the two composites is attributed to the reasons discussed above.

Table 1 shows the pore texture parameters and the removal efficiencies of the composites (average of three measurements). Compared with EG/ZnO-1, EG/ZnO-2 

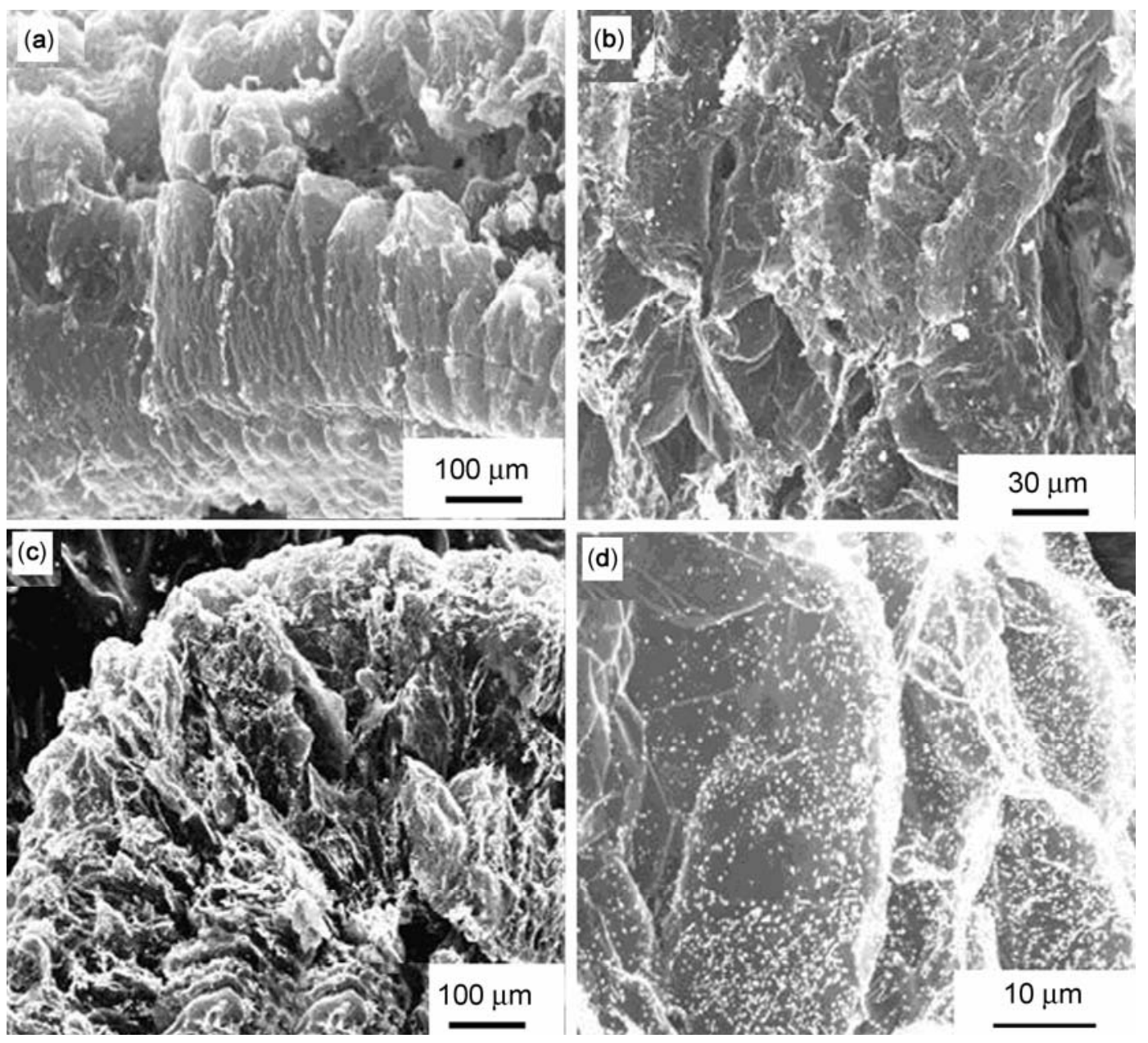

Figure 1. SEM micrographs showing surface and interior structures of composites.

Table 1. Pore texture parameters and MB removal capacities of the composites.

\begin{tabular}{lccccc}
\hline Sample & $\begin{array}{c}\mathrm{W}_{\mathrm{ZnO}} \\
(\mathrm{wt} \%)\end{array}$ & $\begin{array}{c}\text { Exfoliation volume } \\
(\mathrm{ml} / \mathrm{g})\end{array}$ & $\begin{array}{c}\mathrm{S}_{\mathrm{BET}} \\
\left(\mathrm{m}^{2} / \mathrm{g}\right)\end{array}$ & $\begin{array}{c}\text { Adsorption efficiency } \\
(3 \mathrm{~h} ; \%)\end{array}$ & $\begin{array}{c}\text { Removal efficiency } \\
(3 \mathrm{~h} ; \%)\end{array}$ \\
\hline Pure EG & 0 & 250 & 50 & $31 \cdot 4$ & $33 \cdot 0$ \\
EG/ZnO-1 & 25 & 160 & 44 & $26 \cdot 0$ & 70 \\
EG/ZnO-1 & 35 & 150 & 43 & $25 \cdot 1$ & 75 \\
EG/ZnO-2 & 25 & 35 & 15 & $25 \cdot 2$ & $74 \cdot 9$ \\
EG/ZnO-2 & 35 & 30 & 13 & $22 \cdot 4$ & $83 \cdot 6$ \\
EG/ZnO-2 & 45 & 30 & 13 & $20 \cdot 0$ & $89 \cdot 0$ \\
EG/ZnO-2 & 55 & 25 & 12 & $18 \cdot 3$ & $73 \cdot 9$ \\
EG/ZnO-2 & 65 & 20 & 10 & $18 \cdot 0$ & \\
\hline
\end{tabular}

exhibited far lower expanded volumes and specific surface areas, which could be explained by its dispersed EG particles (based on experimental observation), retracted surface V-type pores (figure 1c) and partly filled inner pores (figure 1d).

\subsection{XRD of the composites}

The XRD patterns of the composites are shown in figure 2. Besides the graphite (002) peaks, all the marked peaks could coincidently be indexed as the hexagonal wurtzite-type $\mathrm{ZnO}$. Compared with EG/ZnO-2, EG/ZnO1 exhibited less and weaker $\mathrm{ZnO}$ diffraction peaks, which might be due to its higher expanded volume (table 1) and larger $\mathrm{ZnO}$ particle agglomeration (figures $1 \mathrm{a}, \mathrm{b}$ ). In $\mathrm{EG} / \mathrm{ZnO}-2$, the relative high intensity of the $\mathrm{ZnO}$ (101) peak indicated anisotropic growth and presented a preferred orientation of the crystallites, but which was not the case for EG/ZnO-1. The reason needed further study. 


\subsection{Removal of MB by the composites}

The composites only had the adsorption capacity of EG in the absence of UV irradiation, which was influenced by the EG content and the pore texture parameters of the composites. In the presence of UV irradiation, the composites had the adsorption capacity of EG and the photocatalysis capacity of $\mathrm{ZnO}$ at the same time. Table 1 showed that the difference between the adsorption efficiency and removal efficiency of the pure EG was negligible, but which was not the case for the composites. This suggested that the $\mathrm{ZnO}$ was necessary for the decomposition of $\mathrm{MB}$, and the decomposition efficiency could be approximately denoted by the difference of removal efficiency and adsorption efficiency, as shown in (5). For $\mathrm{EG} / \mathrm{ZnO}-1$, the removal efficiency increased from 70 to

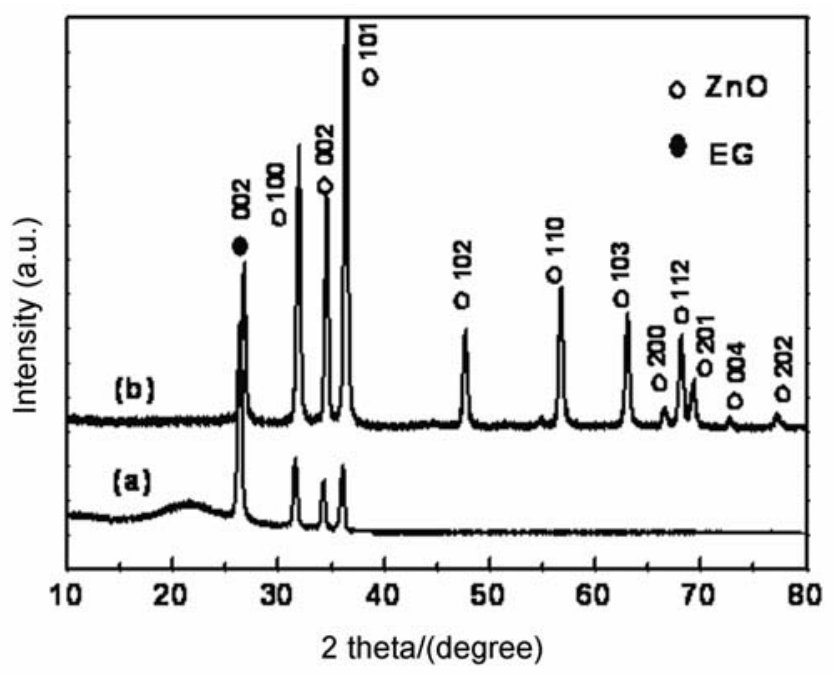

Figure 2. XRD patterns of composites.

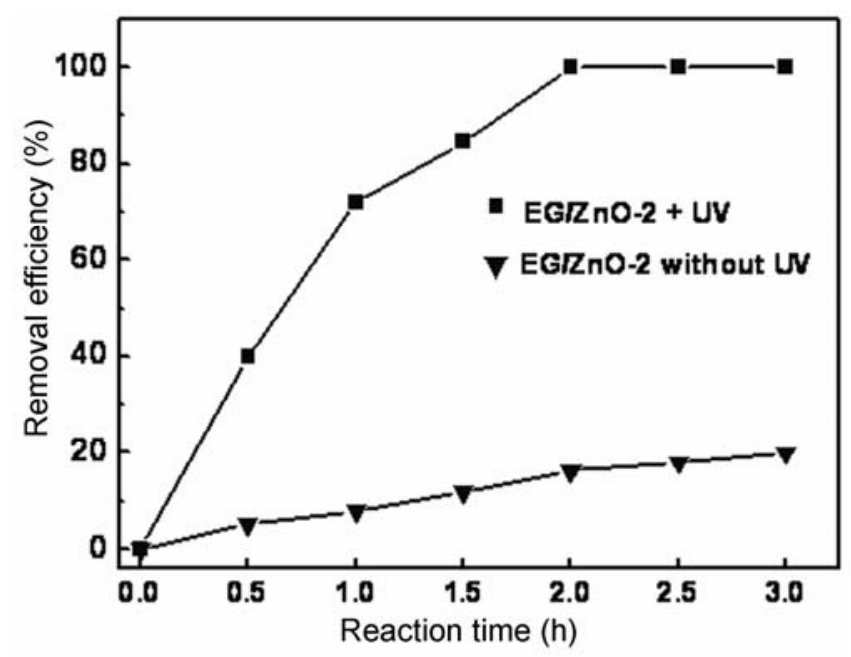

Figure 3. Effect of reaction time on adsorption and removal efficiency of EG/ZnO-2 with $45 \% \mathrm{ZnO}$.
$75 \%$ with increasing the $\mathrm{ZnO}$ content from 25 to $35 \%$ of the maximum content. For the same $\mathrm{ZnO}$ content of $35 \%$, EG/ZnO-2 exhibited higher removal efficiency than EG/ZnO-1 did, which might be due to its more fine and uniform distribution of $\mathrm{ZnO}$ particles. For EG/ZnO-2, the removal efficiency increased with increasing the $\mathrm{ZnO}$ content up to $45 \%$ and then decreased, which could be explained by the two opposing effects with increasing the $\mathrm{ZnO}$ content. Increasing the $\mathrm{ZnO}$ content could strengthen the photocatalytic capacity of the composites, but weaken the adsorption capacity. Moreover, the bulk density of the composites would increase with increasing the $\mathrm{ZnO}$ content, causing the increase in the amount of the composites sink to bottom. Therefore, the optimal $\mathrm{ZnO}$ content in EG/ZnO-2 was $45 \%$.

Figure 3 shows the effect of reaction time on the adsorption and removal efficiency of the EG/ZnO-2 with $45 \% \mathrm{ZnO}$. The removal efficiency reached to $100 \%$ after $2 \mathrm{~h}$ UV irradiation, but the adsorption efficiency was only $20 \%$ at $3 \mathrm{~h}$. This result indicated that, for the EG/ZnO-2, the decomposition efficiency of $\mathrm{ZnO}$ was the primary cause of the MB removal, while the main function of $E G$ was to make the $\mathrm{MB}$ absorbed onto the composites and provide decomposition site. Due to the characteristic pore structure of EG, a large amount of UV could permeate through the pores and irradiate onto the $\mathrm{ZnO}$ particles on EG. Therefore, the removal system could provide a threedimensional decomposition environment for the absorbed $\mathrm{MB}$, which was not the case for the current supports, such as silica gel, glass, ceramic membrane and stainless steel. Loading photocatalyst on EG could combine the adsorption capacity of EG and the photocatalytic capacity of the photocatalyst, and effectively remove dye in water ( $\mathrm{Li}$ et al 2008). However, this work did not deal with the effect of photocatalyst-loading technique on the removal capacity of EG/photocatalyst composites. In this paper, we used two different techniques to load photocatalyst on EG and found that photocatalyst-loading method strongly influenced the textural characteristic and dye removal capacity of EG/photocatalyst composites.

\section{Conclusions}

By using two ZnO-loading methods, we successfully synthesized two EG/ZnO composites. Compared with $\mathrm{EG} / \mathrm{ZnO}-1$, the distribution of $\mathrm{ZnO}$ particles in $\mathrm{EG} / \mathrm{ZnO}-2$ was more fine and uniform, and the permissible $\mathrm{ZnO}$ content in EG/ZnO-2 was larger. Under UV irradiation, the composites had the adsorption capacity of EG and the photocatalysis capacity of $\mathrm{ZnO}$ at the same time. EG/ZnO-2 was more effective and useful on removing $M B$ compared with EG/ZnO-1. After $2 \mathrm{~h} \mathrm{UV}$ irradiation, the removal efficiency could reach $100 \%$ by using the EG/ZnO-2 containing $45 \% \mathrm{ZnO}$, and the decomposition efficiency of the $\mathrm{ZnO}$ was the primary cause of MB removal. 


\section{Acknowledgements}

This work was supported by the National Science Foundation for Distinguished Young Scholars of China (No. 50925522) and the National Science Foundation of China (No. 50975247).

\section{References}

Chung D D L 1987 J. Mater. Sci. 224190

Daneshvar N, Rasoulifard M H, Khataee A R and Hosseinzadeh F 2007 J. Hazard. Mater. 14395

Inagaki M, Toyoda M, Kang F Y, Zhang Y P and Shen W C 2003 New Carbon Mater. 18241

Kang F Y, Zhang Y P, Zhao H N, Wang L N, Shen W C and Inagaki M 2003 New Carbon Mater. 18161

Li J H, Li M, Li J, Xu Y, Jia Z X and Li M 2008 Ultrason. Sonochem. 15949
Li J T, Li M, Li J H and Sun H W 2007 Ultrason. Sonochem.14 62

Lizama C, Freer J, Baeza J and Mansilla H 2002 Catal. Today 76235

Quintana M, Ricra E, Rodriguez J and Estrada W 2002 Catal. Today 76141

Savoskin M V, Yaroshenko A P, Lazareva N I, Mochalin V N and Mysyk R D 2006 J. Phys. Chem. Solids 671205

Shornikova O N, Sorokina N E and Avdeev W 2008 J. Phys. Chem. Solids 691168

Toyoda M and Inagaki M 2000 Carbon 38199

Tryba B, Morawski A W, Kalenczuk R J and Inagaki M 2003 Spill Sci. Technol. Bull. 8569

Wang H and Xie C S 2008 J. Phys. Chem. Solids 692440

Yeber M C, Rodriguez J, Freer J, Baeza J, Duran N and Mansilla H 1999 Chemosphere 391679

Yue X Q, Zhang R J, Wang W Y, Wang L Q and Yang Y L 2008 Mater. Lett. 621919

Zheng Y P, Wang H N, Kang F Y, Wang L N and Inagaki M 2004 Carbon 422603 